\title{
Devolved amalgamation
}

\author{
Stephen Hancocks OBE \\ Editor-in-Chief
}

The BDJ Upfront section includes editorials, letters, news, book reviews and interviews. Please direct your correspondence to the News Editor,

Kate Quinlan at k.quinlan@nature.com. Press releases or articles may be edited, and should include a colour photograph if possible.

$\mathrm{T}$ here is a near-universal recognition that the 2014 Minamata Convention on the reduction of mercury in the environment is 'a good thing.' For us in dentistry, while acknowledging the importance of the measure, an immediate panic was due to our reliance to date then, and still now in many counties of the world, on the incorporation of mercury in dental amalgam as a restorative material. Indeed, we are familiar with the phrase 'the phase down of dental amalgam' which has been given a further recent airing with the publication of four statements, one from each of the countries and separate health jurisdictions that make up the UK: England, Wales, Scotland and Northern Ireland. . $^{1,2,3,4}$

The four plans follow broadly the same pattern of listing prevention, alternative materials and techniques and service delivery. They were prompted by EU Regulation 2017/852 on mercury which requires member states to set out a national plan on the measures they intend to implement to phase down the use of dental amalgam. This in turn prompted me to seek out and read in full the text of the Minamata Convention on Mercury, which I confess I had not previously done. ${ }^{5}$ It does make for some interesting observations. Sixty-seven pages in extent, it consists primarily of 35 Articles and five Annexes detailing the measures agreed.

I was immediately struck by the first and foremost exclusion from the Convention in Appendix A: 'Products essential to civil protection and military uses.' These may, no doubt, be essential. But who can know and who can quantify this? Clearly governments, or at least the armed forces they represent, stepped in with caveats at an early stage. This may be wholly understandable but it does nothing to put the problem into perspective. Are all our other efforts dwarfed by the potential military usage?
The second matter to strike me was that dental amalgam is not even mentioned as such until Annex A Part II, page 56 of the document. Here, admittedly there is a list of nine 'measures to be taken by a Party to phase down the use of dental amalgam, [which] shall take into account the Party's domestic circumstances and relevant international guidance and shall include two or more of the measures of the following list...' Not surprisingly the four national plans each list at least the two required. reality we know that this simply is not going to happen.

So where does all this leave us? Various papers in this journal have pointed out the obvious truths that there are no viable wholesale current alternatives to dental amalgam, nor any in prospect of research and development. However, it is clear that until or unless there is an extension or re-opening of the Convention to bring an actual deadline date to the phase out of amalgam, as long as governments around the world, including the

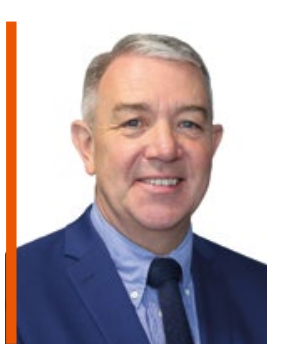

\section{'Are all our other efforts dwarfed by the potential military usage?'}

My third observation is that while all other uses of mercury are given a 'phase out' deadline, dental amalgam is the only exception (as we know) which has a 'phase down' designation and no deadline date. We have much to thank our hard working dental politicians for in helping to negotiate this but, in reading the four national plans, the cynical side of me cannot help wonder the extent that behind-the-scenes lobbying from governments (or treasuries) and from other third party funders of dental care may have been brought to bare on this. There is repeated emphasis placed on the costs of changing from amalgam to non-mercury containing materials and techniques.

Each of the plans and the Minamata Convention itself lay great emphasis on the fact that the best way to cease using dental amalgam is through the prevention of dental caries. No one could possibly disagree with this in principle, which makes it an ideal (and less costly) political position, but in
UK, continue to select 'at least two' measures from the prescribed phase down list all will be well. As one of the plans states, we should not be complacent but rarely can 'down and out' have had such a vital impact on state policies.

\section{References}

1. Department of Health and Social Care. Dental amalgam: plan to phase down use in England. 2019. Available at https://www.gov.uk/government/publications/dentalamalgam-plan-to-phase-down-use-in-england (accessed August 2019).

2. Welsh Government. A National Plan to phase down the use of dental amalgam in Wales. 2019. Available at https://gov.wales/sites/default/files/publications/2019-07/national-plan-to-phase-down-the-use-ofdental-amalgam-in-wales.pdf (accessed August 2019).

3. Scottish Government. Amalgam dental fillings: action plan. 2019. Available at https://www.gov.scot/publications/amalgam-dental-fillings-action-plan (accessed August 2019).

4. Department of Health. Dental Amalgam Plan. 2019. Available at www.health-ni.gov.uk/publications/dental-amalgam-plan (accessed August 2019).

5. UN Environment. Minamata Convention on Mercury. Available at http://www.mercuryconvention.org (accessed August 2019).

https://doi.org/10.1038/s41415-019-0677-9 